\title{
The Multi-Site Order Fulfillment-Planning Model: A Global Corporation Case Study
}

\author{
Yin-Yann Chen*, Chiung-Wen Shih, Hsiao-Yao Fan \\ National Formosa University, Yunlin, Taiwan \\ *yyc@nfu.edu.tw
}

\begin{abstract}
A multi-site order fulfillment-planning model for the thin film transistor-liquid crystal display (TFT-LCD) panel industry is proposed. The order allocation problem is solved using a mathematical programming model considering practical characteristics, including product structures, customer preferences, alternative bill-of-material, and production constraints. A practical global corporation case in Taiwan will be employed to testify the feasibility of the proposed order fulfillment-planning model. Besides, the adaptability and comparison of different planning approaches in an environment of various market demands are discussed. Through the analysis of experiments, the proposed mathematical programming model is found to be better than the current popular method.
\end{abstract}

\section{Keywords: Order fulfillment; order allocation; TFT-LCD; multi-site planning; mathematical programming}

\section{Introduction}

A general module factory of the small and medium sized thin film transistor-liquid crystal display (TFT-LCD) panel industry exists in a "make-to-order" production system. The received orders from customers include an order "due date". To address market demands that change quickly, customers require a shorter due date. Thus, a panel manufacturer that can quickly respond to and satisfy the requirements of customers is more likely to stand out from other competitors. The capacity allocation and completion date of orders for the module factories are complicated by the constraints created by customers who designate certain key materials and production factories, resulting in sourcing from different material suppliers and locations. When variability is high and unexpected customer requirements of orders occur, shortening the production cycle time and fulfilling the order quickly by employing an efficient resource allocation mechanism have become a critical issue in the operations management of panel manufacturers. Numerous industries and scholars have explored the available-to-promise (ATP) allocation problem for order fulfillment planning in the past literature. Current inventory and available capacity are examined based on confirmed orders from customers to evaluate whether new orders should be taken and when the due date should be. In the small and medium sized TFT-LCD industry, the panel manufacturer is in an inferior position, and the brand channel partners dominate the price and lead the market trend. Consequently, the manufacturers located in Taiwan and China have to develop a better production planning to keep the cost competitive advantage, aside from considering the complicated manufacturing process and constraints on product characteristics.

In the small and medium sized TFT-LCD panel industry, the front-end manufacturing processes (array and cell) require highly automated machine devices. Currently, most enterprises still select Taiwan as a production location due to the expensive equipment and complicated techniques. Meanwhile, in the back-end module process, TFT substrates and other materials are assembled and delivered to downstream customers after testing. In this process, a large amount of labor is required for production, and thus most enterprises move their manufacturing factories to China. Moreover, enterprises usually have several array, cell and module factories at the same time due to the growing demand for panels in recent years, and constitute the so-called multi-stage multi-site production network structure. The research subject is the module process, a process after TFT substrates are cut into pieces without considering the front-end array and cell processes. The small and medium sized TFT-LCD panel industry exists in a pull-based production system, and its production plan is activated by customer orders. Aside from product types, quantities, and the due date of orders, this research also discusses other characteristics, such as ABOM recognition and manufacturing sites designated by customers. There are many types of ABOMs for a product because the customer designates components. Before the customer 
places the order, panel manufacturers will evaluate and certify the quality, compatibility, and cost of every ABOM for a certain product. There is a possibility for the module factory to choose among a series of feasible ABOMs, which fit the planning performance goal, and release the material to production when planning the production scheduling.

Due to the ABOM concept of the TFT-LCD industry, not only the existed constraints of production capacity, due date and quantity, but also the possibility that the same product is made of different combination of materials should be considered, and thus the planning complexity is greatly raised. In addition, the end-brand customers take the production abilities of panel manufacturers into consideration, and require that their products be shipped from specific manufacturing sites to meet certain quality levels. Each small and medium sized TFT-LCD product is mainly composed of seven key components. These components are glass, color filter, polarizer, source-IC or gate-IC, source-PCB or gate PCB, backlight, and touch panel. In the TFT-LCD industry, the key components used by panel producers in the manufacturing process are influenced by the following two factors. (1) Customers require that certain materials should be provided by suppliers with qualified production standards. (2) Customers designate certain component suppliers for strategic cooperation. This condition leads to a phenomenon that the same products are possibly made of different components due to the specific requirements of customers. Moreover, different components have to be combined together due to specification and compatibility issues, such as electric properties. If the supply source of a certain component needs modification or replacement, the other corresponding components should be changed as well. This is the concept of alternative bill-of-material (ABOM), which is unique to the TFT-LCD industry. Panel manufacturers will match materials that have specification compatibility issues, or suppliers that have cooperative relationships, to form different ABOMs. When a customer order is received, the products will be matched with feasible ABOMs according to the requirements specified in the order.

\section{Literature Review}

Maravelias and Sung (2009) indicate that strategic (long-term) planning determines the structure of the supply chain (e.g. facility location). Medium-term (tactical) planning is concerned with decisions such as the assignment of production targets to facilities and the transportation from facilities to warehouses to distribution centers. Finally, short-term planning is carried out on a daily or weekly basis to determine the assignment of tasks to units and the sequencing of tasks in each unit. At the production level, short-term planning is referred to as scheduling. Many manufacturers today have multiple plants around the world to support their global markets. For a global manufacturer with multiple production sites, there are location differences in production and logistics capability, lead times and costs. To satisfy customers with the quantities and due dates they requested, the manufacturer has to consider simultaneously the location, the costs, the capacity and the due dates (Tsai \& Wang, 2009). Roux (1999) proposes an approach for solving a multi-stage, multi-product lot-sizing problem in a multi-site environment. The goal is to determine an optimal plan for a multi-site structure, each site being a multi-machine work center. The method alternates between solving a planning and scheduling problem in two separated planning and scheduling modules. A nice feature of the proposed methodology is its modularity. However, the model only considers the most common constraints for the author's generated sample. Carlo (1999) deals with a capacitated master production planning and capacity allocation problem for a multi-plant manufacturing system with two serial stages in each plant. The author develops the iterative heuristic procedures based on the LP (linear programming)-relaxation approach. The problem features considered in this paper are taken from the real-world process industry. The practical multi-site planning application is also found in Timpe and Kallrath (2000) research taken from the chemical industry. They describe a general mixed-integer linear programming model based on a time-indexed formulation covering the relevant features. The model combines aspects related to production, distribution and marketing and involves production plants and sales points. Besides standard features of lot sizing problems, further aspects such as different time scales attached to production and distribution. The similar research considering variable time buckets in a multi-site supply network planning problem is also studied in Lin and Chen (2007).

The order fulfillment-planning model: The headquarters will receive all the orders from customers. After considering the due date of the orders, production capacity of factories, and supply constraints of key materials, the orders are allocated to each module factory. From the viewpoint of the enterprise 
headquarters, a production plan of the module factory in various locations is made. The production resource is planned and the optimization of the order allocation is sought based on the planning goal of creating operational profit for the whole industry.

The mixed integer-programming model: The parameters and decision variables are presented in Table 1 and Table 2.

Table 1: Description of the parameters

\begin{tabular}{|c|c|}
\hline Parameters & Description \\
\hline deiklt & the amount of product $k$ required by order $i$ on location $l$ in period $t$ \\
\hline$e a_{i k a}$ & $\begin{array}{l}\text { Whether order } i \text { recognizes the ABOM (alternative bill of material) } a \text { of the product } k \text {. (ea } a_{i k a}=1 \\
\text { represents the order recognizes it; otherwise, } e a_{i k a}=0 . \text {.) }\end{array}$ \\
\hline$e m_{i j}$ & $\begin{array}{l}\text { Whether order } i \text { is manufactured in factory } j \text { designated by customers. }\left(e m_{i j}=1 \text { represents that the }\right. \\
\left.\text { order is manufactured in the designated factory } j \text {; otherwise, } e m_{i j}=0 .\right)\end{array}$ \\
\hline$p r_{i k}$ & the unit price of order $i$ for product $k$ \\
\hline$p c_{j k a}$ & unit production cost of product $k$ with $\mathrm{ABOM} a$ in factory $j$. \\
\hline$i c_{j k a}$ & unit inventory cost of product $k$ with $\mathrm{ABOM} a$ in factory $j$. \\
\hline$o c_{j k a}$ & unit outsourcing cost of product $k$ with $\mathrm{ABOM} a$ in factory $j$. \\
\hline$s c_{j k a}$ & unit shortage cost of product $k$ with ABOM $a$ in factory $j$. \\
\hline$t c_{j l}$ & unit transportation cost from factory $j$ to the designated customer location $l$. \\
\hline$c a_{j t}$ & available capacity of factory $j$ in period $t$. (hours) \\
\hline$c f_{j k a}$ & capacity consumption factor of product $k$ with $\mathrm{ABOM} a$ in factory $j$. (hours) \\
\hline$y e_{j k a}$ & yield rate of product $k$ with $\mathrm{ABOM} a$ in factory $j$. \\
\hline$i q_{i j k a}$ & initial inventory amount of order $i$ for product $k$ with $\mathrm{ABOM} a$ in factory $j$ \\
\hline lotsize $e_{j i k a t}^{\min }$ & minimal production lot size of order $i$ for product $k$ with ABOM $a$ at factory $j$ in period $t$. \\
\hline
\end{tabular}

Table 2: Description of the decision variables

\begin{tabular}{|c|c|}
\hline Variables & Description \\
\hline$X Q_{i j k a t}$ & $\begin{array}{l}\text { production amounts of order } i \text { for product } k \text { with ABOM (alternative bill of material) } a \text { at factory } j \text { in } \\
\text { period } t \text {. }\end{array}$ \\
\hline$Y_{i j k a t}$ & $\begin{array}{l}\text { binary variables, } Y_{i j k a t}=1 \text {, if order } i \text { for product } k \text { with ABOM } a \text { is processed at factory } j \text { in period } t \text {; } Y_{i j k a t} \\
=0 \text {, otherwise. }\end{array}$ \\
\hline$I Q_{i j k a t}$ & inventory amounts of finished products of order $i$ for product $k$ with ABOM $a$ at factory $j$ in period $t$. \\
\hline$O Q_{i j k a t}$ & outsourcing amounts of order $i$ for product $k$ with ABOM $a$ at factory $j$ in period $t$. \\
\hline$B Q_{i j k a t}$ & backorder amounts of order $i$ for product $k$ with $\mathrm{ABOM} a$ at factory $j$ in period $t$. \\
\hline$T Q_{i j k a l t}$ & $\begin{array}{l}\text { transportation amounts of order } i \text { for product } k \text { with ABOM } a \text { from factory } j \text { to customer location } l \text { in } \\
\text { period } t \text {. }\end{array}$ \\
\hline
\end{tabular}

The whole mixed integer-programming model is presented in Appendix A in detail.

The objective function: The objective function (A.1) represents the maximum profit, that is, total income minus total production cost, inventory cost, outsourcing cost, shortage cost, and transportation cost.

The constraints: Equation (A.2) is the order requirement satisfaction constraint. Equation (A.3) is the inventory amount of finished products at the beginning of the planning horizon in each site. Equation (A.4) is the inventory relation of the products in each site. Equation (A.5) represents that the total capacity consumed by each factory to manufacture products in the module process during the planning horizon should not exceed the upper limit of the available capacity in the factory. The equation means that when the order recognizes the $\mathrm{ABOM}$ of the product, the factory in the module process can start production with the ABOM to meet the requirements of the order $\left(e a_{i k a}=1\right)$. On the other hand, when the order does not recognize the ABOM (ea $i k a=0)$, the site cannot start the production with the ABOM. Equation (A.7) and (A.8) is the judgment relation of designated production site by the order in the module process. When $e m_{i j}=1$, it means the factory in the module process can manufacture the products required by order $i$. Therefore, $X Q_{i j k a t}$ can be larger than 0 ; if $e m_{i j}=0$, it means the module factory cannot manufacture the products required by the order. $X Q_{i j k a t}$ has to be equal to zero. Equations (A.9) are the constraints of the minimal production lot size for product $k$ with $\mathrm{ABOM} a$ of each site in the module process. Equations (A.10) and (A.11) are the non-negativity restriction of decision variables. Equation (A.12) is the restriction of binary variables. 


\section{The case illustration and computational results}

The core business of the case corporation is the module process of small and medium sized TFT-LCD panels. There are three factories symbolized as F1, F2, and F3. The research includes five sales products, Type-A, Type-B, Type-C, Type-D, and Type-E. In this case, the module factory receives 20 orders at the planning start time, that is, March 1, as shown in Table 3. The content of the order includes relevant information, such as product type, quantity, due date, price, customer location, ABOM recognized by customers, and designated manufacturing site.

Table 3: The received orders at the planning start time (March 1)

\begin{tabular}{|c|c|c|c|c|c|c|c|c|c|c|}
\hline \multirow{2}{*}{ Order } & \multirow{2}{*}{$\begin{array}{l}\text { Product } \\
\text { Type }\end{array}$} & \multirow{2}{*}{ Quantity } & \multirow{2}{*}{ Due date } & \multirow{2}{*}{$\begin{array}{l}\text { Unit Price } \\
\text { (\$USD) }\end{array}$} & \multirow{2}{*}{$\begin{array}{l}\text { Customer } \\
\text { Location }\end{array}$} & \multicolumn{2}{|c|}{ Recognized ABOM } & \multicolumn{3}{|c|}{ Designated Factory } \\
\hline & & & & & & AB0M1 & ABOM2 & F1 & F2 & F3 \\
\hline 1 & $\mathrm{C}$ & 10000 & March 15 & 8.0 & Shanghai & 0 & 0 & - & $\bullet$ & $\bullet$ \\
\hline 2 & $\mathrm{C}$ & 3000 & May 11 & 8.0 & Shanghai & o & o & & $\bullet$ & $\bullet$ \\
\hline 3 & B & 3000 & March 10 & 8.0 & Shanghai & ० & ० & $\bullet$ & $\bullet$ & \\
\hline 4 & A & 2000 & March 15 & 6.8 & Shanghai & & ० & $\bullet$ & & \\
\hline 5 & $\mathrm{C}$ & 2000 & March 5 & 8.0 & Shanghai & & o & & $\bullet$ & $\bullet$ \\
\hline 6 & D & 10000 & April 3 & 9.2 & Shanghai & & ○ & & $\bullet$ & $\bullet$ \\
\hline 7 & E & 10000 & April 10 & 10.3 & Shanghai & & o & & $\bullet$ & \\
\hline 8 & D & 10000 & March 29 & 9.2 & $\mathrm{HK}$ & o & & & & $\bullet$ \\
\hline 9 & B & 2000 & May 12 & 8.0 & HK & o & & $\bullet$ & & \\
\hline 10 & A & 2500 & March 18 & 6.8 & HK & ○ & & $\bullet$ & & \\
\hline 11 & B & 6000 & March 16 & 8.0 & HK & O & & $\bullet$ & & \\
\hline 12 & $\mathrm{C}$ & 5000 & April 10 & 8.0 & HK & o & & & & $\bullet$ \\
\hline 13 & E & 15000 & March 25 & 10.3 & HK & ○ & & & $\bullet$ & \\
\hline 14 & D & 3000 & March 23 & 9.2 & HK & & o & & $\bullet$ & $\bullet$ \\
\hline 15 & A & 20000 & April 5 & 6.8 & $\mathrm{HK}$ & & O & $\bullet$ & & \\
\hline 16 & E & 2000 & March 28 & 10.3 & Shanghai & O & O & & $\bullet$ & \\
\hline 17 & D & 3000 & March 9 & 9.2 & Shanghai & O & O & & $\bullet$ & $\bullet$ \\
\hline 18 & B & 2000 & March 2 & 8.0 & $\mathrm{HK}$ & o & o & $\bullet$ & - & $\bullet$ \\
\hline 19 & D & 10000 & March 16 & 9.2 & HK & o & o & & - & $\bullet$ \\
\hline 20 & $\mathrm{D}$ & 10000 & May 11 & 9.2 & HK & ○ & ○ & & $\bullet$ & $\bullet$ \\
\hline
\end{tabular}

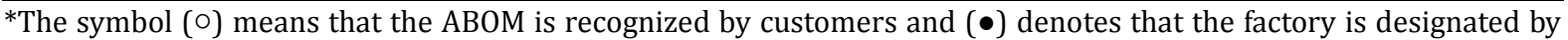
customers to produce.

The multi-site production allocation-planning problem is solved by using the famous optimization package ILOG CPLEX 12.5. The optimal order allocation results are illustrated in Table 4.

Table 4: The order allocation results of the first phase.

\begin{tabular}{|c|c|c|c|c|c|}
\hline Order & & Quantity & Confirme & ABOM & Production Factory \\
\hline 1 & $\mathrm{C}$ & 10000 & March 15 & 1 & F3 \\
\hline 2 & $\mathrm{C}$ & 3000 & May 11 & 1 & F3 \\
\hline 3 & B & 3000 & March 10 & 1 & F1 \\
\hline 4 & A & 2000 & March 15 & 2 & F1 \\
\hline 5 & $\mathrm{C}$ & 2000 & March 5 & 2 & F3 \\
\hline 6 & D & 10000 & April 3 & 2 & F3 \\
\hline 7 & $\mathrm{E}$ & 10000 & April 10 & 2 & $\mathrm{~F} 2$ \\
\hline 8 & D & 10000 & March 29 & 1 & F3 \\
\hline 9 & B & 2000 & May 12 & 1 & F1 \\
\hline 10 & A & 2500 & March 18 & 1 & F1 \\
\hline 11 & B & 6000 & March 16 & 1 & F1 \\
\hline 12 & $\mathrm{C}$ & 5000 & April 10 & 1 & F3 \\
\hline 13 & $\mathrm{E}$ & 15000 & March 25 & 1 & $\mathrm{~F} 2$ \\
\hline 14 & D & 3000 & March 23 & 2 & F3 \\
\hline 15 & A & 20000 & April 5 & 2 & F1 \\
\hline 16 & E & 2000 & March 28 & 1 & $\mathrm{~F} 2$ \\
\hline 17 & D & 3000 & March 9 & 1 & F3 \\
\hline
\end{tabular}




\begin{tabular}{llllll}
18 & B & 2000 & March 2 & 1 & F3 \\
19 & D & 10000 & March 16 & 1 & F3 \\
20 & D & 10000 & May 11 & 1 & F3 \\
\hline
\end{tabular}

\section{Experimental analysis}

The multi-site planning method refers to the proposed mathematical programming method in the research. Furthermore, the traditional often-used method in the industry is called the as-is method. The as-is method considers the order due date and the cost information of each product manufactured in different factories. There is an assumption that all the orders arrive at the planning start time. The constraint of materials is not considered. The order is sequenced according to the EDD (earliest due date) rule. The order with the highest priority is produced first. If the due dates of the orders are the same, the order with the largest amount of demand is produced first. Due to the constraints of the recognized ABOM and designated production site, after the orders are sequenced, each order is filtered to determine the factory that can process the order. The considerations of filtering the orders include the factory's capability and customer preference. Next, allocate the order by sequence to the suitable factory for processing. The factory with the lowest production cost will be allocated first. If the capacity of that factory cannot afford the order, the factory with the second lowest cost will be chosen to process the order.

The scale of fluctuation between the peak period and the slack period is large in the TFT-LCD industry. The environment cannot remain in the same loading. This study explores how the demands of orders influence the performance of various planning methods. There are six levels for this factor. The ratios of the demand of orders versus total capacity, that is, system loading, are $25 \%, 50 \%, 75 \%, 90 \%, 100 \%$, and $125 \%$, respectively. Figure 1 shows how the multi-site planning method influences the total profit performance under various system loads. As Figure 1 illustrates, when the demand of the orders is little, that is, the system load of the module factory is low, almost all the orders can be released for processing in the factory with the lowest cost due to the large surplus capacity without being influenced by the capacity of the factory when allocating the orders. Therefore, the industry profit performance among all the methods is the same. However, when the system load exceeds $75 \%$, the optimal mathematical programming model proposed in the research performs better than the as-is rule. Based on the analysis, when the demand of orders raises, the total profit increases. However, the growing rate is decreasing because the key factor that constrains the production is the capacity of the module factory.

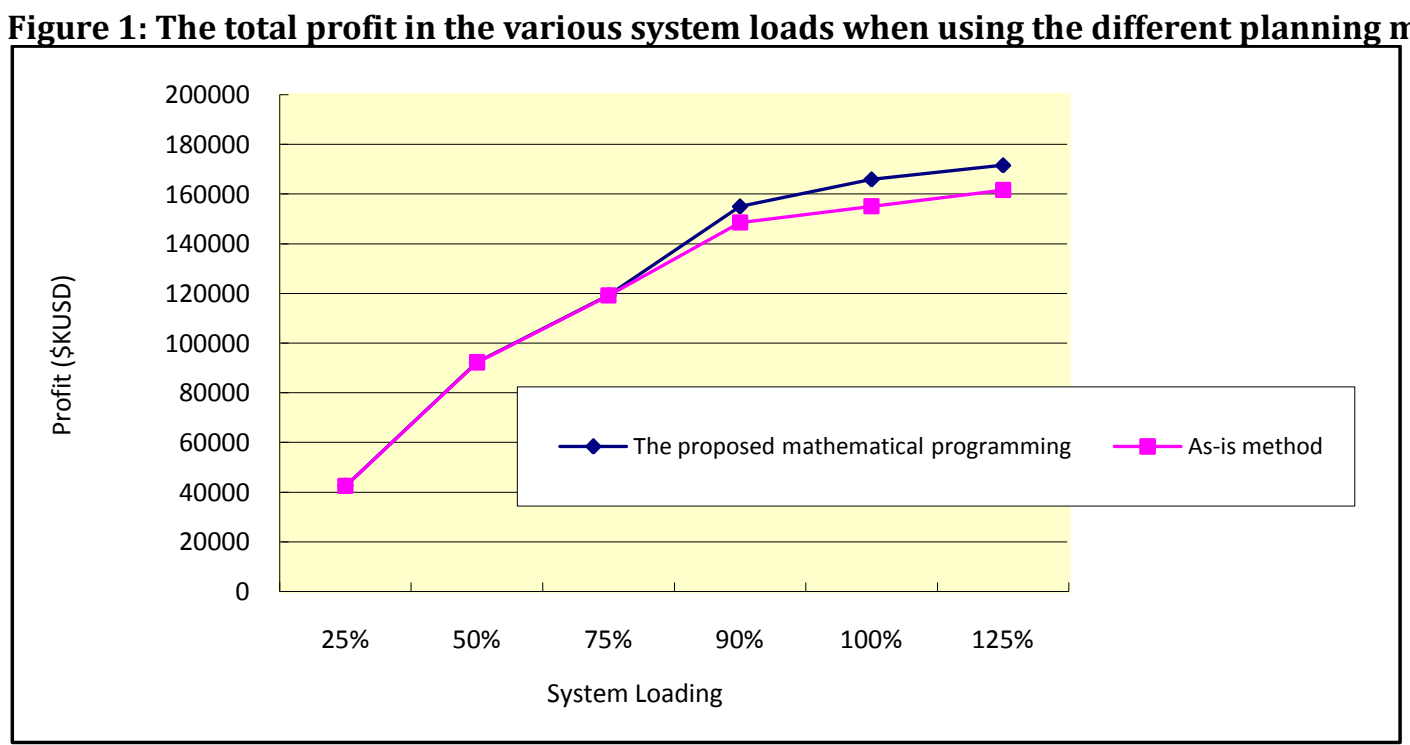

\section{Conclusion}

In this research, taking the small and medium sized TFT-LCD panel industry as an example, the relevant characteristics that should be considered when fulfilling orders (e.g., product hierarchy, limited capacity 
of factories, supply availability of key materials, and special requirements of customers) are discussed under the pull-based multi-site production environment. For the multi-site allocation planning issue in the module process, addressed by the optimal mathematical programming model to solve the problems. Based on the experimental analysis, the planning result of the proposed mathematical programming model is found to be better than the current popular method.

\section{Appendix A: Mathematical programming model}

- Objective function

$$
\begin{aligned}
\operatorname{Max} & \sum_{i} \sum_{j} \sum_{k} \sum_{a} \sum_{l} \sum_{t}\left(p r_{i k} \times T Q_{i j k a l t}\right)-\sum_{i} \sum_{j} \sum_{k} \sum_{a} \sum_{t}\left(p c_{j k a} \times X Q_{i j k a t}\right) \\
& -\sum_{i} \sum_{j} \sum_{k} \sum_{a} \sum_{t}\left(i c_{j k a} \times I Q_{i j k a t}\right)-\sum_{i} \sum_{j} \sum_{k} \sum_{a} \sum_{t}\left(o c_{j k a} \times O Q_{i j k a t}\right) \\
& -\sum_{i} \sum_{j} \sum_{k} \sum_{a} \sum_{t}\left(s c_{j k a} \times B Q_{i j k a t}\right)-\sum_{i} \sum_{j} \sum_{k} \sum_{a} \sum_{l} \sum_{t}\left(t c_{j l} \times T Q_{i j k a l t}\right)
\end{aligned}
$$

\section{- Constraints}

$$
\begin{aligned}
& \sum_{j} \sum_{a} T Q_{i j k a l t} \leq d e_{i k l t} \quad, \forall i, k, l, t \\
& i q_{i j k a}=I Q_{i j k a t} \quad, \forall i, j, k, a, t=0 \\
& I Q_{i j k a, t-1}+\left(X Q_{i j k a t} \times y e_{j k a}\right)+O Q_{i j k a t}+B Q_{i j k a t}-B Q_{i j k a, t-1}-\sum_{l} T Q_{i j k a l t}=I Q_{i j k a t}, \forall i, j, k, a, t \\
& \sum_{i} \sum_{k} \sum_{a}\left(X Q_{i j k a t} \times c f_{j k a}\right) \leq c a_{j t} \quad, \forall j, t \\
& X Q_{i j k a t} \leq e a_{i k a} \times M^{1} \quad \forall i, j, k, a, t, M^{1} \text { refers to large enough number } \\
& Y_{i j k a t} \leq e m_{i j}, \forall i, j, k, a, t \\
& X Q_{i j k a t} \leq Y_{i j k a t} \times M^{2} \quad, \forall i, j, k, a, t, M^{2} \text { refers to large enough number } \\
& X Q_{i j k a t} \geq l o t s i z e_{i j k a t}^{\min } \times Y_{i j k a t}, \forall i, j, k, a, t \\
& X Q_{i j k a t}, I Q_{i j k a t}, O Q_{i j k a t} \geq 0, \forall i, j, k, a, t \\
& T Q_{i j k a l t} \geq 0 \quad, \forall i, j, k, a, l, t \\
& Y_{i j k a t} \in\{0,1\} \quad, \forall i, j, k, a, t
\end{aligned}
$$

\section{References}

Carlo, V. (1999). Multi-plant production planning in capacitated self-configuring two-stage serial systems. European Journal of Operational Research, 119(2), 451-460.

Lin, J. \& Chen, Y. Y. (2007). A multi-site supply network planning problem considering variable time buckets- A TFT-LCD industry case. The International Journal of Advanced Manufacturing Technology, 33(9), 1031-1044.

Maravelias, C. T. \& Sung, C. (2009). Integration of production planning and scheduling: Overview, challenges and opportunities. Computers \& Chemical Engineering, 33(12), 1919-1930.

Roux, W. (1999). Planning and scheduling in a multi-site environment. Production Planning \& Control, 10(1), 19-28.

Timpe, C. H. \& Kallrath, J. (2000). Optimal planning in large multi-site production networks. European Journal of Operational Research, 126(2), 422-435.

Tsai, K. M. \& Wang, S. C. (2009). Multi-site available-to-promise modeling for assemble-to-order manufacturing: An illustration on TFT-LCD manufacturing. International Journal of Production Economics, 117(1), 174-184. 